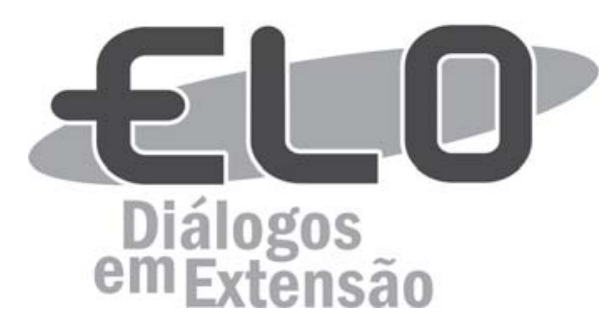

\title{
Extensão universitária e formação discente: caracteristicas do processo educativo da Incubadora Tecnológica de Cooperativas Populares
}

\author{
Emerson Alcides da Silva ${ }^{1}$ Edgard Leite de Oliveira ${ }^{2}$
}

\begin{abstract}
Resumo: A extensão universitária é um importante campo de formação para graduandos por articular os aprendizados acadêmicos com as demandas sociais. No contexto da Economia Solidária, a Incubadora Tecnológica de Cooperativas Populares é um Programa de Extensão que promove ações de incubação e assessoria a grupos populares. Durante essas ações, estudantes de diversos cursos passam por uma formação teórica e prática, na qual são instigados a desenvolver o senso crítico sobre seu papel na sociedade. Este artigo tem por objetivo identificar as características do processo educativo da ITCP-UFV e verificar de que forma elas podem contribuir para formação de profissionais aptos a atuar na Economia Solidária. A metodologia adotada foi o estudo do tipo etnográfico em educação. Como resultado obteve-se o trabalho em equipe; a autogestão; o aprendizado pela prática; a liberdade e a responsabilidade; o protagonismo juvenil; a vivência dos valores e princípios da Economia Solidária; e a interdisciplinaridade.
\end{abstract}

Palavras-chave: Economia Solidária. Educação. Autogestão. Participação. Graduandos.

Área Temática: Teorias e Metodologias em extensão. Educação. Cooperativismo.

\section{University extension and student training: characteristics of the educational process on the Technological Incubator of Popular Cooperatives}

\begin{abstract}
The university extension has been an important field of professional formation for students, therefore, it articulates the academic learnings with the needs of Society. In the context of the solidarity economy, the Technological Incubator for Popular Cooperatives has been promotes incubation and advisory services to popular groups. During these actions, students from the diverse courses undergo theoretical and practical training, in which they are encouraged to develop a critical sense of their role in society. The purpose of this article is to identify the characteristics of the educational process of the ITCP-UFV, and to verify how it contribute to the training of professionals capable of acting in the solidarity economy. The methodology adopted was the study of the ethnographic type in education. The characteristics identified are: teamwork; selfmanagement and horizontal processes; learning by practice; freedom and responsibility; youth protagonism; experience of the values and principles of the solidarity economy; Interdisciplinarity.
\end{abstract}

Keywords: Theories and Methodologies in extension. Education. Participation. Students.

\section{Extensión universitaria y formación discente: caracteristicas del proceso educativo de la Incubadora Tecnológica de Cooperativas Populares}

Resumen: La extensión universitaria es un importante campo de experimentación y formación para estudiantes, pues, articula los aprendizajes académicos con las necesidades de la sociedad. En el contexto

\footnotetext{
${ }^{1}$ Universidade Federal de Viçosa, Bacharel em Cooperativismo, Graduando em Pedagogia, Rua Manoel Clemente, 120, Bom Jesus, Viçosa MG, emerson.alcides@ufv.br telefone: (31) 988698152 .

${ }^{2}$ Universidade Federal de Viçosa, Orientador do artigo, Doutorado em Educação, Professor Adjunto, Violeira, s/n, Viçosa MG, Coordenador do Projeto Reciclagem

Popular e Solidária: Protagonismo das Catadoras e dos Catadores na Construção da Coleta Seletiva, executado pela ITCP-UFV, edgard.leite@ufv.br, (31) 38993908
} 
de la economía solidaria, la Incubadora Tecnológica de Cooperativas Populares promueve acciones de incubación y asesoría a grupos populares. Durante estas acciones, estudiantes de diversos cursos pasan por una formación teórica y práctica, en la cual son alentados a desarrollar un sentido crítico sobre su papel en la sociedad. El objetivo de este artículo es identificar las características del proceso educativo de la ITCP-UFV, y verificar de qué forma contribuye a la formación de profesionales aptos para actuar en la economía solidaria. La metodología adoptada fue el estudio de tipo etnográfico en educación. Como resultado tenemos: el trabajo en equipo; la autogestión y procesos horizontales; el aprendizaje por la práctica; la libertad y responsabilidad; el protagonismo juvenil; la vivencia de los valores y principios de la economía solidaria; y la Interdisciplinariedad.

Palabras clave: Economía Solidaria. Educación. Autogestión. Participación. Estudiantes.

\section{Introdução}

A Extensão Universitária é um processo no qual o conhecimento científico e os saberes populares interagem promovendo transformações (FREIRE, 1977). A Incubadora Tecnológica de Cooperativas Populares da Universidade Federal de Viçosa (ITCP-UFV) é um Programa de Extensão, que desde 2003 desenvolve ações de incubação, assessoria e fomento a empreendimentos econômicos solidários (EES) da cidade de Viçosa-MG e região. Processo que envolve o fortalecimento nos âmbitos econômico, organizativo, social e político de associações, cooperativas e grupos informais que atuam em diversas áreas, como agricultura familiar, reciclagem popular, artesanato, etc.

Para desenvolver essas ações, a incubadora conta com uma equipe de trabalho diversificada composta por técnicos (profissionais graduados e pós-graduados), discentes de diversos cursos de graduação e docentes da UFV, que atuam na orientação das ações desenvolvidas (COSTA, SILVA E DOURADO, 2017). Ora ou outra a equipe conta também com a participação de intercambistas estrangeiros. Todos os integrantes das incubadoras são denominados "formadores". Na ITCP-UFV a dinâmica de trabalho ocorre a partir de processos horizontais, democráticos e autogestionários nos quais o protagonismo dos graduandos é parte fundamental da metodologia.

A ITCP-UFV tem sede na casa 3 da Vila Matoso, Campus da UFV, Viçosa-MG. Vinculada ao Departamento de Economia Rural (DER), tem em seu efetivo vários integrantes do curso de cooperativismo. Normalmente, tem na coordenação pelo menos um docente deste departamento. Tratase de um programa multidisciplinar aberto a estudantes de quaisquer cursos de graduação e institucionalmente vinculado à Pró-Reitoria de Extensão e Cultura (PEC).

Além dos processos socioeconômicos voltados aos empreendimentos, a ITCP-UFV tem importante papel na formação discente, ao possibilitar que jovens de vários cursos, origens e culturas, interajam com um coletivo diverso e com membros dos EES, enriquecendo a própria formação a partir da experimentação profissional. Esta concepção de educação/ação promovida pela incubadora está fundamentada nos princípios da Economia Solidária e na educação popular de Paulo Freire.

O fato de a incubadora ser uma organização educativa estruturada em bases associativas e democráticas, que promove a formação de seus integrantes, e a partir deste, a formação dos membros dos EES, fez com que o primeiro autor deste artigo considerasse a possibilidade de ingressar no programa. Assim o fiz em abril de 2014, no cargo de técnico em cooperativismo e visualizei neste trabalho, a oportunidade de estudar seu processo educativo. Como a proposta de trabalho a priori seria de dois anos, identifiquei na pesquisa qualitativa do tipo etnográfica em educação a melhor forma de investigar este fenômeno.

Na oportunidade, recém bacharel em cooperativismo, estava preparado para atuar em cooperativas, associações, ou em organizações que fomentem estes tipos de grupos. Possuía experiência de trabalho com empreendimentos solidários, além de inserção em movimentos sociais. Entretanto, durante a graduação participei de dois projetos de extensão em que, no primeiro, em que atuei como voluntário, não existia orientação docente, ficando toda responsabilidade de diagnóstico planejamento e execução, com a equipe discente. No segundo, já com vínculo de bolsista, contei com uma orientação rígida e não dialógica. Ambas experiências negaram os princípios que norteiam a extensão universitária.

Outrossim, sob a ótica educacional, as indagações iniciais que levaram a incubadora a se tornar um objeto de estudo foi compreender algumas questões. Como: a incubadora se relaciona com os demais atores da Economia Solidária? O que leva os discentes a se interessarem por este programa? Quais as contribuições da ITCP -a estes estudantes? Como se dá o envolvimento/interação dos 
indivíduos/parte, com o coletivo/todo? Como a pedagogia de Paulo Freire contribui com este processo? Qual a contribuição dos princípios da Economia Solidária à dinâmica deste grupo?

O objetivo deste trabalho, desta maneira, é identificar as características do processo educativo da ITCP-UFV, e verificar de que forma elas podem contribuir para formação de profissionais aptos a atuar na área da Economia Solidária. Entendo por características educacionais a estrutura de trabalho, a visão de mundo, a organização interna e as metodologias do programa, que oportunizarão à equipe de trabalho compreender a dinâmica de organização da Economia Solidária e seus atores sociais.

O recorte temporal dessa pesquisa compreende um período de 24 meses, sendo de abril de 2014 a abril de 2016, período em que a incubadora executou um projeto aprovado no Programa Nacional de Incubadora de Cooperativas Populares (PRONINC) que viabilizou a contratação de técnicos com o propósito de atuar e/ou prestar assessoramento aos empreendimentos, e, apoio técnico educacional aos graduandos.

A relevância deste trabalho vem da própria educação, pois, se para a educação escolar, a literatura é farta quanto à formação de professores, no campo da formação de educadores da Economia Solidária nem tanto. Para a Economia Solidária, a literatura científica diz muito sobre a educação voltada aos integrantes dos EES, mas há poucas referências sobre a formação dos educadores que atuam neste campo. Em conformação a essa necessidade, Brasil (2015, p. 31) e o Plano Estadual de Economia Solidária de Minas Gerais (2015) trazem entre as diretrizes para a Economia Solidária, a necessidade de investimentos na educação de educadoras e educadores populares.

Com a finalidade de responder ao objetivo proposto pela pesquisa utilizei o que Silva $(1995$, p. 87$)$ denomina importação de discurso, ou seja, retiro o discurso científico relacionado ao estudo da educação formal de seu contexto original e o abstraio de suas relações de produção para inseri-lo no contexto da educação/formação de educadores da Economia Solidária.

\section{Revisão de literatura}

A Economia Solidária se configura como alternativa de trabalho e renda para pessoas deixadas à margem do mundo do trabalho formal. Sua origem remonta a pouco depois do capitalismo industrial, como reação ao espantoso empobrecimento dos artesãos provocado pela difusão das máquinas e da organização fabril da produção (SINGER, 2002, p. 24).

Entre as primeiras experiências solidárias, temos a sociedade cooperativa de Robert Owen (1773 1858), que segundo Singer (2002, p. 26) e Gaiger e Laville (2009, p. 163), propunha não apenas um simples barateamento do sustento dos pobres, mas uma mudança completa no sistema social. Além de Owen, também tivemos as experiências solidárias de Proudhon (1809 - 1865) e os pioneiros de Rochdale (1844). No Brasil desde o início do século XX (SINGER, 2002, p. 122), a Economia Solidária ganha forças a partir da década de 1980 a com a organização de trabalhadores das empresas recuperadas diante dos debates sobre a globalização (FRANÇA FILHO, 2006; SINGER, 2002).

Para Gaiger e Laville (2009) com este desenvolvimento as experiências de

(...) economia solidária multiplicaram-se rapidamente, em diversas formas: coletivos de geração de renda, cantinas populares, cooperativas de produção e comercialização, empresas de trabalhadores, redes e clubes de troca, sistemas de comércio justo e de finanças, grupos de produção ecológica, comunidades produtivas autóctones, associações de mulheres, serviços de proximidade, etc. (p. 162).

Diante desta variedade de iniciativas populares frente às desigualdades sociais, Schiochet (2009) visualiza a Economia Solidária como possibilidade de luta por direitos, especialmente pelo direito ao trabalho associado e à promoção de formas solidárias de organização. Com base nas Políticas Nacionais de Economia Solidária (COSTA 2011; BRASIL, 2010a, 2015), podemos entender que todo EES deve ter a autogestão e o capital solidário como princípios, e a partir deles construir os conhecimentos necessários ao seu desenvolvimento.

Deste modo, a Economia Solidária apresenta-se como uma forma de organização do trabalho na qual o ser humano é mais importante que o capital e pode ser entendida como um conjunto de atividades que apresentam, entre si, a primazia da solidariedade sobre interesses individuais e o ganho material, 
por meio da socialização dos recursos produtivos (GAIGER E LAVILLE, 2009, p. 162).

Aquela multiplicidade de experiências tornou-se um importante movimento social em busca de novas relações de trabalho e geração de renda a partir da valorização do ser humano. Junto a Tal diversidade de iniciativas surge também, seus apoiadores, que Santos e Carneiro (2008) denominam agentes externos, tais como “organizações da sociedade civil (ONG's), igrejas, incubadoras universitárias e movimentos sociais que atuam no campo e na cidade" (p. 9). Entre as organizações de assessoria, apoio e fomento à Economia Solidária, as universidades passam a desempenhar forte papel com ações de ensino, pesquisa e extensão.

Para dar suporte a esta extensão universitária que dialoga e problematiza com a comunidade, o Fórum de Pró-Reitores de Extensão da Rede de Educação Profissional e Tecnológica (FORPROEXT) orienta, através da Política Nacional de Extensão Universitária (2012), que tal ação deva se realizar imbuída pelo "princípio constitucional da indissociabilidade entre ensino, pesquisa e extensão, isto é, como um processo interdisciplinar, educativo, cultural, científico e político que promove a interação transformadora entre Universidade e outros setores da sociedade" (p. 15).

A UFV desenvolve ações de ensino, pesquisa e extensão em diversas áreas. No campo da Economia Solidária, tais ações ocorrem principalmente a partir do Programa de Extensão Universitária Incubadora Tecnológica de Cooperativas Populares. Um Programa de Extensão Universitária

(...) trata-se de um conjunto articulado de projetos e outras ações de Extensão (Cursos, Eventos, Prestação de Serviços), preferencialmente integrando as ações de Extensão, Pesquisa e Ensino. Tem caráter orgânico-institucional, clareza de diretrizes e orientação para um objetivo comum, sendo executado a médio e longo prazo (PEC UFFS, on-line).

Como programa vinculado a Pró-Reitoria de Extensão e Cultura (PEC) da UFV, a ITCP alicerça suas ações nos cinco princípios da extensão universitária, promovendo incubação e assessorias para geração de trabalho e renda aos EES de Viçosa e região. A saber, este modelo de extensão interativa tem como princípios norteadores (i) a Interação dialógica, onde os saberes científicos e sociais se encontram a partir de metodologias ativas e participativas; (ii) a Interdisciplinaridade e interprofissionalidade, que traz a articulação de modelos científicos e do conhecimento de várias ciências; (iii) a Indissociabilidade ensino - pesquisa - extensão onde os três pilares universitários fecundam a transformação social; (iv) o Impacto na formação do estudante o qual, com a presença da orientação pedagógica, e o estabelecimento de objetivos permitam seu pleno desenvolvimento; (v) o Impacto e transformação social, em que, as ações extensionistas realmente promovam o desenvolvimento social (FORPROEXT, 2012).

As Incubadoras Tecnológicas de Cooperativas Populares foram idealizadas em 1992 como parte da Ação da Cidadania contra a fome (SILVA, 2015; BOTELHO et al., 2015). De acordo com Costa, Silva e Dourado (2017), tais iniciativas "surgem na busca de aproximação de demandas sociais urgentes, como o desemprego, e a pobreza com os saberes científicos que se orientam pela organização dos trabalhadores por meio da autogestão e do trabalho associado" (p. 20).

Arelaro (2005, p. 43) coloca as incubadoras como um "movimento de resistência surgido nas universidades, frente às desigualdades sociais exacerbadas pelas políticas neoliberais que assolavam o país". Para Costa, Silva e Dourado (2017), entre os papéis das incubadoras está a promoção de debates teóricos e práticos voltado ao desenvolvimento das iniciativas de Economia Solidária. Nesse contexto de lutas, a ITCP-UFV surgiu por iniciativa de professores e alunos do curso de Administração com Habilitação em Cooperativismo da UFV, hoje curso de Bacharelado em Cooperativismo desta instituição (COSTA, SILVA E DOURADO, 2017).

Ao longo de 15 anos, passaram pela Incubadora mais de 200 estudantes de 21 cursos de graduação da UFV; 20 professores de diferentes departamentos (COSTA, SILVAE DOURADO, 2017); 11 técnicos(as) graduados; além de 9 intercambistas do México e França. Essa equipe foi responsável pela incubação de 20 empreendimentos e assessoria a mais de 100 iniciativas de Economia Solidária, integrando atividades de ensino, pesquisa e extensão. Outro papel das incubadoras está na formação dos membros dos empreendimentos.

Ao propósito, a equipe da ITCP-UFV recebe formação reflexiva na perspectiva da educação popular. É nesta lógica educativa que os formadores e membros dos empreendimentos assumem novos valores e acentuam o papel contestatório da educação popular de caráter associativo (GADOTTI, 2009, p. 
11). Esta educação diferenciada se faz necessária, pois, como estamos inseridos em uma sociedade que se ampara na lógica competitiva de organização social, a prática da Economia Solidária, no seio do capitalismo, nada tem de natural. Ela exige dos indivíduos que dela participam um comportamento social pautado pela solidariedade e não mais pela competição (SINGER, 2005a, p. 16). Assim, podemos entender que é a partir da educação que se institucionalizam os valores da Economia Solidária.

Com objetivo de superar essa condição, Singer (2005b, p. 16) explicita que é preciso uma reeducação coletiva. Sobre a educação na Economia Solidária, Singer (1999) acredita que ela deva vir na prática da autogestão, todavia, tal educação não acontece de forma automática, haja vista, que muitas pessoas se inserem em EES não a partir dos valores solidários.

Deste modo, um dos passos necessários ao desenvolvimento da Economia Solidária é uma educação coletiva, em que os educadores envolvidos com seu incremento reeduquem suas práticas ao constituírem a formação junto aos membros dos empreendimentos solidários. Para Singer (2005) "o verdadeiro aprendizado dá-se com a prática, pois, o comportamento econômico solidário só existe quando é recíproco" (p. 17).

Junto a isto, o trabalho de extensão promovido pelas incubadoras deve permitir à sua equipe a vivência dos princípios e valores da Economia Solidária, possibilitando a institucionalização de novos processos sociais. Diante da demanda por formação das lideranças dos EES, geralmente expressa durante os trabalhos de incubação, constituem-se como objetivos da ITCP-UFV,

(...) a formação de agentes da economia popular solidária na universidade, bem como na sociedade; valorizar a extensão universitária dialógica; construir e socializar novos conhecimentos e tecnologias sociais, instigando o debate e a compreensão de outras concepções de desenvolvimento, além de construir novos valores baseados nos princípios da economia solidária (COSTA, 2013, p. 27).

Esta formação/educação deve se pautar nas características necessárias ao desenvolvimento dos EES, denominada por Borges (2014) de perfil ético. É por meio da vivência junto aos empreendimentos - em que se estreitam relações em busca do entendimento do perfil ético dos grupos para poderem desenvolver o trabalho de extensão dialógica - que os formadores discentes da ITCP-UFV têm a possibilidade de conhecer e praticar os valores baseados nos princípios da economia solidária. É desta maneira que terão a possibilidade de construir e institucionalizar as práticas da Economia Solidária, construídas juntos aos membros dos empreendimentos. Assim, como ocorre com os membros dos empreendimentos, os formadores da incubadora

(...) que se formam em um meio em que prevalece a Economia Solidária vivem desde cedo situações definidas por comportamentos recíprocos de ajuda mútua. Aprenderão que as pessoas diferem, mas que essas diferenças provêm do meio e da educação; que ninguém é tão forte que não precise do auxílio dos outros e que a união faz a força (KRUPPA, 2005, p. 18).

Conforme Brasil (2010b, p. 53) a Economia Solidária se pauta em dez princípios. Quais sejam: (i) Autogestão; (ii) Democracia; (iii) Cooperação; (iv) Centralidade do Ser Humano; (v) Valorização da Diversidade; (vi) Emancipação; (vii) Valorização do Saber Local; (viii) Valorização da Aprendizagem; (ix) Justiça Social na Produção; (x) Cuidado com o Meio Ambiente. Para que ocorra a institucionalização deste processo solidário é preciso que a formação das educadoras e educadores da Economia Solidária seja pautada nestes princípios.

\section{Metodologia}

Para essa investigação, busquei a abordagem qualitativa junto à técnica de pesquisa do tipo etnográfica em educação (MATTOS, 2011). Sandín Esteban (2010, p. 130) explicita que a pesquisa qualitativa em educação abrange basicamente aqueles estudos que desenvolvem os objetivos da compreensão dos fenômenos socioeducativos e a transformação da realidade. Embora a investigação qualitativa em educação seja de reconhecimento recente, possui longa tradição e suas características ajudam os investigadores qualitativos a compreender sua metodologia em contexto histórico (BOGDAN E BIKLEN, 1994). 
Os autores Bogdan e Biklen (1994) afirmam que a investigação qualitativa possui cinco características. A fonte direta de dados é o ambiente natural, constituindo o investigador o instrumento principal. Os dados recolhidos são descritos em forma de palavras ou imagens, não de números. Os investigadores qualitativos interessam-se mais pelo processo que pelo seu resultado ou produto. Os dados são analisados de forma indutiva. E, por último, o significado, a perspectiva do participante, é de importância vital neste tipo de investigação.

Quanto à pesquisa do tipo etnográfica em educação, seu "objetivo é documentar, monitorar e encontrar o significado da ação" (MATTOS, 2011, p. 51). A preferência pelo procedimento de pesquisa do tipo etnográfica em educação decorre de suas características. A primeira está na visão holística sobre a interdisciplinaridade do ambiente pesquisado. Assim, observam-se os modos como esses grupos sociais ou pessoas conduzem suas vidas com o objetivo de revelar o significado cotidiano, nos quais as pessoas agem (MATTOS, 2011, p. 51). A segunda característica, contribuição importante da etnografia à pesquisa qualitativa na observação de grupos sociais, é o longo período de observação, de um a dois anos (ANDRÉ, 1995, p. 28), o que na investigação de situações sociais, permite visualizar o mesmo fenômeno, em diversas situações. Por fim, a terceira característica, que permite visualizar a organização investigada como um todo, constitui aquilo que André (1995, p. 42) classifica de três dimensões da pesquisa etnográfica. Isto é, as dimensões: institucional ou organizacional; a instrucional ou pedagógica; e, a sociopolítica/cultural.

A primeira dimensão permitiu conhecer como se organiza o meio social e quais as relações de forças existentes na ITCP-UFV. A segunda contribuiu para identificar como ocorre o aprendizado/ formação a partir dessa organização; e a terceira mostrou a relação do grupo envolvido (equipe da incubadora), durante o período de investigação, com toda a macroestrutura. Todavia, uma ressalva deve ser feita. Como alertam Cunha e Ribeiro (2010), o etnógrafo deve ser cauteloso, uma vez que "ele pode não ser capaz de abranger holisticamente a complexidade do fenômeno, considerando tamanhas influências existentes que interferem nas relações sociais das organizações" (p. 11).

Após a descrição, os dados foram organizados em categorias sociais, das quais, o protagonismo e a vivência foram definidas a priori, haja vista sua ligação com o movimento estudantil, que proporciona a seus integrantes espaços de liderança e autodesenvolvimento. Para isso, a investigação seguiu o que Moraes (1999, p. 4) define como cinco etapas do processo investigativo: (i) Preparação das informações; (ii) Unitarização ou transformação do conteúdo em unidades; (iii) Categorização ou classificação das unidades em categorias; (iv) Descrição; e, (v) Interpretação.

\section{Resultados}

\section{Trabalhos Realizados}

De 2014 a 2016 foram realizados pela ITCP-UFV: 8 diagnósticos, 8 planejamentos estratégicos, 88 reuniões de acompanhamento e desenvolvimento das ações com os empreendimentos, 32 oficinas em temas diversos (análise viabilidade, contabilidade, aspectos produtivos, Economia Solidária, cooperativismo), 16 intercâmbios dos EES incubados, 7 intercâmbios de integrantes do coletivo com outras incubadoras, organização de 12 reuniões do Fórum Regional de Economia Solidária da Zona da Mata mineira (FREPS-ZMM) em várias cidades da região, 4 Feiras de Economia Solidária, 13 Assembleias Gerais da ITCP, e 9 seminários de formação ou espaços semelhantes.

Este total de 197 atividades demandou organização prévia, e embora não tenha sido possível quantificar, houve diversas reuniões de equipes voltadas ao planejamento e execução das atividades. Em média, foram necessárias uma reunião preparatória no caso das reuniões de acompanhamento dos empreendimentos e até cinco reuniões preparatórias para a realização de seminários, fóruns e intercâmbios. Com Tais atividades, a Incubadora respondeu a cinco projetos com bolsas para técnicos e graduandos, tendo em 2015 uma equipe com 43 integrantes.

Cada evento realizado se constituiu do esforço das equipes em acolher as solicitações dos EES, diagnosticar a necessidade, planejar as ações, implementar as propostas, sistematizar e avaliar seus resultados. Em sua maioria, as ações foram organizadas em coletivo, permitindo a participação ativa dos graduandos. Todavia, em muitos espaços a condução ficou nas mãos dos técnicos ou docentes, fato que diminuiu a proposta de protagonismo estudantil, e por consequência, a possibilidade de aprendizado pela prática. 
Este exercício de preparar e executar as atividades internas e externas é que se constitui nos espaços formativos da ITCP-UFV, pois, cada integrante da equipe executora tem a possibilidade de assumir papéis e colocar seus conhecimentos em prática. Entre eles, são necessários a leitura de material de apoio, a construção da proposta metodológica, o planejamento da execução da proposta com objetivo de prever possíveis falhas, o registro escrito e em fotos e/ou vídeos dos espaços, o agendamento e a confirmação das reuniões, a mediação/diálogo com os grupos, a sistematização dos resultados e o feedback aos grupos.

É no exercício destas ações, e por meio da assunção de responsabilidades, que cada indivíduo põe em prática toda sua bagagem de conhecimentos. Neste caso, diante de uma proposta pedagógica de formação discente, o papel dos técnicos e dos docentes é criar as condições necessárias para que cada integrante colabore com seus conhecimentos. Tudo isso favorece o processo ensino/aprendizagem e aumenta a qualidade dos resultados.

\section{Estrutura e Parcerias}

A Incubadora se constitui num espaço democrático, de fácil acesso a seus integrantes, e aos empreendimentos econômicos solidários. Dispõe de estrutura física e equipamentos necessários à realização dos trabalhos, e atendimento aos projetos parceiros. Isto se deve aos projetos aprovados e executados e à articulação institucional com a Universidade por meio da PEC e do DER.

Além disso, há relação direta com projetos dos departamentos de Ciências Sociais, Educação, Solos, Fitotecnia, Economia Doméstica, Nutrição e Direito. Quanto à rede de articulação, tem-se o Projeto Interação - Responsabilidade e Meio Ambiente; o Grupo de Pesquisa e Extensão em Comunicação, Democracia e Práticas Sociais; o Programa TEIA, que articula diversas ações de extensão e o evento Troca de Saberes; a Rede Raízes da Mata; a Empresa de Assistência Técnica e Extensão Rural do Estado de Minas Gerais (EMATER-MG); o Centro de Tecnologias Alternativas da Zona da Mata (CTA-ZM); dentre outros. Tendo a incubadora o know-how para organização de atividades econômicas com grupos solidários, é a partir dessa rede de articuladores que as significativas ações se tornam possíveis.

\section{Organização Interna}

Com intuito de realizar todos estes trabalhos e articulações, a incubadora organiza seu coletivo semelhante a um EES estruturada em três níveis: Assembleia Geral, Coordenação Geral e Equipes de Trabalho. A Assembleia Geral possui encontros mensais nos quais todos integrantes (docentes, discentes, técnicos, intercambistas) têm obrigatoriedade de participar e igual direito à voz e ao voto. A segunda instância, a Coordenação Geral, é composta por docentes, técnicos e por pelo menos um representante discente de cada uma das seis equipes de trabalho. Ela se reúne semanalmente e tem autonomia para tomar decisões urgentes, mas que não tenha grande impacto no grupo.

Ambas instâncias olham a incubadora como um todo, são deliberativas e, entre outras atribuições, decidem as necessidades de formação coletivas, ingresso ou saída de membros, alocação de recursos financeiros e materiais e encaminham decisões quanto à solicitação de apoio feita pelos empreendimentos e/ou projetos parceiros.

A terceira instância contou de 2014 a 2016 com seis equipes de trabalho, cada uma composta por um técnico e vários discentes. Estas equipes são distribuídas em duas linhas de atuação sendo, (i) os Segmentos, onde ficam alocados os empreendimentos incubados; e (ii) os Núcleos, equipes que trabalham transversais aos Segmentos. Na primeira linha estão o Segmento Artesanato \& Cultura (SAC), desenvolvendo atividades com empreendimentos do setor de artesanato e um grupo quilombola; o Segmento Agricultura Familiar \& Agroecologia (AFA), atendendo a grupos de produtores rurais e redes de comercialização; e o Segmento Reciclagem Popular e Solidária (RP), que atende aos coletivos de catadores de materiais recicláveis.

Na segunda linha temos: o Núcleo de Comunicação e Eventos (NCE), responsável pela comunicação da incubadora e dos empreendimentos; o Núcleo Econômico, Contábil e Jurídico (NECJ), que trabalha com os empreendimentos a partir da organização econômica e jurídica, além do apoio técnico à própria incubadora; e o Núcleo Fóruns e Redes (NFR), que articula a incubadora e os empreendimentos a partir dos Fóruns de Economia Solidária, da organização em redes e das Feiras de Economia Solidária. 
Embora a Assembleia Geral e a Coordenação sejam as responsáveis pela formação do coletivo em um âmbito mais amplo, cada equipe de trabalho é responsável por pensar a própria formação a partir das necessidades que surgem no desenvolvimento do trabalho de incubação e/ou assessoria aos ESS, ou, de conformidade com a sua área de atuação.

Em meu ingresso na incubadora, fui escolhido pelo SAC e dois meses depois escolhi o NECJ, atuando em ambos. Embora não seja proibida a inserção em duas ou mais equipes, é recomendado que os formadores escolham uma em que se dedique com profundidade. Por isso, até como forma de conhecer melhor a dinâmica do grupo, além da presença continuada nestas duas equipes, ao longo dos 24 meses transitei por todas as outras, acompanhando algumas ações de forma presencial e suas reuniões por meio dos relatórios, ou informes nas reuniões semanais.

Embora a Incubadora conte com uma coordenação docente, por atribuição, responsável por todas as suas ações, há na ITCP uma relação de confiança e profissionalismo, que favorece o protagonismo discente em atender às necessidades do coletivo e dos empreendimentos. Toda ação realizada na Incubadora parte de processos horizontais de decisão, baseados na confiança coletiva e na autogestão. Ademais, a democracia ocorreu porque, no período em que essa pesquisa foi desenvolvida, a coordenadora participou diariamente e ativamente dos planejamentos, escutou, debateu e respeitou as decisões coletivas. Além disso, as relações de poder e liderança ocorreram a partir do conhecimento e do exercício do direito à fala. Neste caso, quem tinha mais experiência na ação a ser realizada, tinha mais conhecimento sobre algum assunto ou tema, assumia a função de líder nos momentos requeridos.

\section{Processo ensino/aprendizagem}

Quanto ao trabalho pedagógico identifiquei que não há um projeto educativo ou político pedagógico definido e estruturado que norteie a formação do grupo. A formação discente vem das práxis, sendo definida a partir da linha de trabalho escolhida e por meio das necessidades dos empreendimentos. Entretanto, há um regimento interno que dispõe sobre questões pedagógicas e organizacionais na forma de acordos coletivos. Quem ingressa como formador na ITCP não tem um caminho formativo certo a cumprir, ao contrário dos empreendimentos incubados, que ao solicitar apoio, passam por uma metodologia de incubação bem estruturada com início, meio e fim. Neste caso, vale uma reflexão sobre a real necessidade de haver este caminho para a formação da equipe, pois, a ausência deste permite que se construam diversos caminhos formativos.

Ao ingressar na Incubadora todo formador escolhe ou é escolhido por uma das equipes, normalmente com base nas áreas de interesse. Porém, identifiquei que o fato de ingressar neste caminho não garante um aprendizado, pois, este só se efetiva se o indivíduo se envolver com as atividades/ trabalhos e se o trabalho/orientação dos técnicos e docentes permitir a emergência do protagonismo. É a relação discente/docente/técnico que permitirá, ou não, aos graduandos aprenderem com os processos sociais nos quais a incubadora se envolve. E o maior aprendizado vem da relação destes com os membros dos EES.

Pelas observações, foi perceptível que, na maioria dos casos, os integrantes do grupo se envolvem com as atividades de sua própria equipe, mas não acompanham o trabalho realizado pelas outras. Isto pode ser um bom indicativo, quando olhamos a questão da especialização para o trabalho, mas pode ser ruim, quando se avalia a partir do princípio da interdisciplinaridade e interprofissionalidade, um dos princípios que norteia as ações de extensão da incubadora. Também identifiquei que alguns formadores discentes evitam assumir trabalhos e responsabilidades, além de se ausentar à espaços coletivos obrigatórios. Nestes casos, apesar de previsto no regimento interno, as ausências sempre foram explicitadas e debatidas, mas em poucos casos as sanções previstas foram aplicadas.

\section{Discussão}

Este trabalho teve por objetivo abordar a importância da extensão universitária para formação discente, em especial, naquilo que Costa (2013, p. 27) denomina de formação de agentes da economia popular solidária nas universidades. Busquei compreender, especificamente, o que há no trabalho extensionista da ITCP-UFV que favorece a formação dos educadores populares para Economia Solidária. O que exponho, portanto, neste trabalho são as características inerentes à prática educativa do programa. Apresento-as didaticamente separadamente, contudo, na prática, esta separação inexiste. Afinal, as ações são vividas em sua complexidade pelos indivíduos. Após a compreensão da dinâmica 
de grupo, os relatórios de assembleias, seminários e algumas reuniões de equipe foram separados e sistematizados para identificação de eventos mais recorrentes. Tendo isso, os dados foram organizados em categorias sociais.

Com intuito de promover a formação de agentes da Economia Solidária na universidade, a ITCPUFV se organiza sob seus princípios e possibilita aos graduandos a experimentação e a condução de práticas educativas, nas quais passam por sensações semelhantes às vivenciadas pelos membros dos empreendimentos solidários. Desse modo, para garantir a validade da pesquisa, assumi no início minha visão de mundo, minimizando as influências que tenho como profissional do cooperativismo e da Economia Solidária. Entendo, assim, que as principais características presentes no processo formativo da ITCP-UFV são: 1. Trabalho em equipe; 2. Autogestão e processos horizontais; 3. Aprendizado pela prática; 4. Liberdade e responsabilidade; 5 . Protagonismo juvenil; 6. Vivência dos valores e princípios da economia solidária; 7 . Interdisciplinaridade e transdisciplinaridade.

\section{Quadro 1 - Características Educativas Destacadas}

\begin{tabular}{|c|c|}
\hline Características & Indicadores \\
\hline Trabalho em equipe. & $\begin{array}{l}\text { Assembleia Geral periódica; Coordenação Geral, } \\
\text { Segmentos e Núcleos com reuniões semanais. }\end{array}$ \\
\hline Autogestão e processos horizontais. & $\begin{array}{l}\text { Distribuição coletiva dos trabalhos entre as equipes, rotatividade } \\
\text { na limpeza e manutenção da casa, construção coletiva } \\
\text { de projetos, respeito às decisões coletivas. }\end{array}$ \\
\hline Aprendizados pela prática. & $\begin{array}{l}\text { Realização de oficinas e espaços de formação para o coletivo e } \\
\text { grupos populares, construção compartilhada de metodologias, } \\
\text { planejamento e realização das feiras, contato com } \\
\text { os grupos populares e com o Poder Público. }\end{array}$ \\
\hline Liberdade e responsabilidade. & $\begin{array}{l}\text { Autonomia do grupo, adesão voluntária, possibilidade } \\
\text { de construir o próprio quadro de horários de trabalho, } \\
\text { compromisso grupal, participação nos espaços coletivos. }\end{array}$ \\
\hline Protagonismo juvenil. & $\begin{array}{l}\text { É um programa que se faz a partir dos estudantes, } \\
\text { poder decisório, assunção de trabalhos. }\end{array}$ \\
\hline $\begin{array}{l}\text { Vivência dos valores e princípios da } \\
\text { Economia Solidária. }\end{array}$ & $\begin{array}{l}\text { Primazia pela igualdade de gênero, relações colaborativas, } \\
\text { transparência nos processos e acesso à informação, oportunidades } \\
\text { compartilhadas, místicas internas como a } \\
\text { mesa da partilha, lanches compartilhados. }\end{array}$ \\
\hline Interdisciplinaridade e transdisciplinaridade. & $\begin{array}{l}\text { Articulação das diversas ciências para realização das propostas } \\
\text { de trabalho e formação, extrapolação das barreiras } \\
\text { acadêmicas, valorização do conhecimento popular, } \\
\text { trabalho articulado com a própria formação acadêmica. }\end{array}$ \\
\hline
\end{tabular}

Fonte: elaborado pelos autores com base em USP (2017)

\section{1 - Trabalho em equipe}

A organização interna da Incubadora se constitui por um coletivo, formado por vários sub-grupos. Diante da fragmentação social promovida pela competição capitalista, essa é a oportunidade dos discentes/educandos vivenciarem as dificuldades enfrentadas pelos membros dos EES no desenvolvimento de ações coletivas. Segundo Matheus (1995, p. 14) o trabalho em equipe não é uma atividade automática ou consequência natural de capacidade técnica ou profissional; é, antes de tudo uma qualidade a ser desenvolvida como propriedade coletiva.

Cada equipe de trabalho possui autonomia para decidir os rumos de suas ações de assessoria aos empreendimentos econômicos solidários. Entretanto, tais ações devem estar conectadas à proposta metodológica da incubadora e às ações definidas em coletivo. No período analisado foram raros os casos em que alguém da incubadora assumiu algum trabalho sozinho, mostrando que a prática da coletividade já está institucionalizada no grupo. Portanto, a organização coletiva que se constitui em diversos sub-grupos de trabalho, reforçam a ideia de formação/trabalho/ aprendizado em equipe como característica da Incubadora. Cardozo (2003, p. 18) diz que ao contrário do trabalho em grupo, onde o resultado é o mais importante, nos trabalhos em equipe, o que importa é o processo. Assim, entendo que a vida em equipe é uma característica do processo formativo da incubadora, pois, fortalece aprendizado da Economia Solidária, principalmente a partir da mediação pedagógica docente. 


\section{2 - Autogestão e processos horizontais}

Para Rufino e Barbieri (2008) “a autogestão consiste na autonomia da coletividade dos membros e da empresa em decidir sobre os destinos, os processos e os resultados dos trabalhos" (p. 17). Podemos colocá-la como uma das características mais importantes na Economia Solidária, pois, representa o compromisso entre seus integrantes. A autogestão é um conceito presente e contraditório no coletivo da ITCP-UFV. Presente, porque sua estrutura em equipes, que distribuem e realizam trabalhos e oportunidades de aprendizado, fazem com que cada integrante se veja como parte do grupo, o que acelera a socialização, o estabelecimento de vínculos e à assunção progressiva dos trabalhos e de responsabilidade. É também contraditório, pois, se trata de uma prática social diferenciada, ante a cultura capitalista individualista. Entre as críticas internas ao próprio coletivo, algumas dizem respeito aos compromissos assumidos e não realizados por um ou mais integrante. Como ensinar aos integrantes dos empreendimentos algo que não se sabe, ou não se vivencia? Rodrigues (2014, p. 27), defende que "o ensino da autogestão deve acontecer pela prática. Não existe um curso de autogestão o qual podemos ensinar seus princípios, mas construída a partir da vivência, em conjunto com o outro".

Ademais, a horizontalidade é intrínseca à autogestão, pois, se esta é parte da organização e distribuição coletiva dos trabalhos, para que ela ocorra, a horizontalidade dos processos dará a todos as mesmas condições e oportunidades de decidir. Para isto, o sistema organizacional da incubadora, juntamente com os processos democráticos e a distribuição dos trabalhos em equipes, convergem para essa prática. Como visto, a autogestão não é um processo de rápida compreensão e execução, sendo necessário um período com intuito de propiciar seu aprendizado. Quanto aos integrantes do coletivo, principalmente os novatos, a institucionalização da autogestão depende estritamente da percepção da liberdade, associada ao senso de responsabilidade, inerente à prática extensionista da ITCP. É a partir da liberdade de assumir a organização dos processos e de interagir com o outro é que a compreensão de seu papel na prática da autogestão se aflora.

\section{3 - Aprendizados pela prática}

Nos primeiros meses de trabalho, uma das principais questões observadas foi como se dava o aprendizado dos discentes, principalmente de quem chega no coletivo. As questões norteadoras foram: Como são recebidos os novos integrantes? Como se ensina/aprende a organização interna e a fazer os trabalhos externos? Este foi um processo difícil, pois, não havia uma técnica específica para detectar o quanto cada novo integrante realmente já sabia e para mensurar o aprendizado continuado.

No entanto, o envolvimento de longo prazo, como propõe a pesquisa etnográfica, permitiu presenciar a alteração de comportamento dos indivíduos. Entre as mudanças, a maturidade com relação aos trabalhos realizados, a crescente assunção de responsabilidade e do direito à fala nos espaços comunitários, e, principalmente, a percepção da elevação da autoestima e da confiança no próprio potencial. Berth (2018, p. 18) denomina este processo de empoderamento, pois, fornece estratégias para libertação individual a partir da emancipação coletiva.

É importante destacar, que para ingressar no coletivo, há processos de seleção nos quais são requisitadas e avaliadas certas habilidades de cada candidato. Tal habilidade é a contribuição inicial do integrante ao grupo, mesmo que este ainda não tenha participado de nenhum processo formativo interno. Todavia, Singer (2002) alerta que, na lógica capitalista, aquele que já possui alguma experiência, acumula vantagens para a próxima competição (processo seletivo), e, é papel da ITCP-UFV combater aquela lógica em todas as suas formas, como gênero, orientação sexual, raça, origem social, entre outras. Assim, houve processos seletivos em que até os menos experientes, ou com menos riqueza de currículo foram os selecionados a integrar o coletivo. A estes, o ingresso na incubadora trouxe possibilidades de aprendizado imensuráveis, e aos veteranos da incubadora, a crença que é possível quebrar paradigmas.

Além disto, na observação da organização para os trabalhos, cada integrante contribuiu com seus conhecimentos de mundo e com a própria formação acadêmica. Esta se constituiu numa prática recorrente, de forma que, o trabalho realizado com os empreendimentos gerava questionamentos à própria equipe. De volta à ITCP, essas indagações levaram as equipes a refletirem sobre suas práticas e a buscarem soluções no coletivo e na literatura. Este processo de planejamento/ação/reflexão é o que Freire $(1991,2000)$ denomina de prática problematizadora. Ademais, este aprendizado se dá numa formação continuada, à medida que os discentes se envolvem com as ações. Corroborando com a pesquisa de Santos e Cruz (2008), na qual os atores definem que, a partir da prática extensionista, 
(...) os universitários aprendem a vida real, aquela que não está nos bancos acadêmicos; os trabalhadores do EES aprendem a usar as ferramentas que a vida lhes negou. A incubação, enfim, é um processo de troca entre dois saberes que se produzem em duas esferas distintas da vida social. É, portanto, um ato pedagógico (p. 9).

Os técnicos e docentes devem criar oportunidades com o intuito de que os integrantes do coletivo desenvolvam suas curiosidades, ajudando-os a projetar em suas vidas profissionais o interesse pela atuação ativa na transformação da sociedade. As ações extensionistas da ITCP-UFV permitem a aquisição e o desenvolvimento destas habilidades para o trabalho e para a vida. Os discentes/ educandos/formadores são motivados para que aprendam a (re)aprender seu papel no desenvolvimento da Economia Solidária, e por consequência, na transformação do país.

Essa característica de aprendizado com o outro a partir das necessidades do trabalho e da vida é um dos pressupostos de Freire (1991), em que ninguém educa ninguém, ninguém educa a si mesmo, os homens se educam entre si, mediatizados pelo mundo. Para Gadotti (2003) "aprendemos com porque precisamos do outro, fazemo-nos na relação com o outro, mediados pelo mundo, pela realidade em que vivemos" (p. 47). Ademais, a prática extensionista é em si mesma o aprendizado pela prática. Isso, quando a extensão é na verdade uma comunicação (FREIRE, 1977).

\section{4 - Liberdade e responsabilidade}

Mesmo que se realizassem trabalhos de extensão a partir da organização em equipes (SAC, AFA, RP, NCE, NECJ, NFR), o que reforça a presença da coletividade, algumas ações acabavam sendo realizadas de forma individualizada. Em ambas as situações, seja no trabalho coletivo ou individualizado, a questão da responsabilidade assumida com os empreendimentos e com o próprio coletivo prevaleceu. Todavia, embora não tenha sido possível quantificar, várias ações atrasaram pela falha de alguns indivíduos. Mesmo considerando tal falha, em sua maioria, a liberdade na condução e execução dos trabalhos levou os discentes a responderem e a respeitarem o compromisso assumido.

Para Freire (1997), ensinar exige aceitação do novo e a rejeição do velho. O novo se faz na proposta de coordenação partilhada, exigindo compromisso mútuo e aceitação da responsabilidade, e o velho está presente na cultura capitalista e individualista, inerente a todos nós. Assim,

O grande problema que se coloca ao educador ou à educadora de opção democrática é com trabalhar no sentido de fazer possível que a necessidade do limite seja assumida eticamente pela liberdade. Quanto mais criticamente a liberdade assuma o limite necessário tanto mais autoridade tem ela, eticamente falando, para continuar lutando em seu nome (FREIRE, 1997, p. 65).

Nesta perspectiva, Borges (2014), em pesquisa com membros de empreendimentos solidários identificou o que chama de perfil ético no trabalho associado, no qual, a liberdade recebida para realizar os trabalhos em grupo levou ao desenvolvimento da consciência de responsabilidade e respeito aos acordos coletivos. Investigando as características educativas a partir da observação do processo social, o qual se dá a partir dos compromissos assumidos, e da organização de cada espaço, acredito que o envolvimento dos formadores (graduandos, técnicos e professores) se traduz no desenvolvimento da consciência crítica de todo o grupo. Toda liberdade conquistada com o desenvolvimento moral e ético geram a responsabilidade para consigo, para com o outro e para com a humanidade, configurando, então, um grau de liberdade demarcado pelo grau de responsabilidade gerado (BORGES, 2014, p. 80).

\section{5 - Protagonismo Juvenil}

Ao falar em educação na perspectiva de Paulo Freire, é preciso que o educando/discente tenha condições de assumir ações em sua totalidade dentro de suas potencialidades. A assunção de responsabilidade atrelada à liberdade para criar e executar tarefas é inerente às ações da incubadora. Menezes e Santos (2001, on-line) definem o protagonismo como "uma participação ativa em ações que vão além das questões relativas à vida privada, como família". Outro aspecto do protagonismo é a "concepção do jovem como fonte de iniciativa, que é ação; como fonte de liberdade, que é opção; e como fonte de compromissos, que é responsabilidade" (MENEZES E SANTOS, 2001, on-line). 
O termo protagonismo surgiu nos anos 1960 com o princípio de fazer com que as narrativas históricas fossem construídas pelos grupos sócio acêntricos; ou seja, por aqueles grupos com poucas representações sociais e políticas, independentemente da quantidade (FERREIRA, 2017, on-line). Na perspectiva da Economia Solidária, Lovato, Yirula e Franzim (2017, p. 11) colocam o protagonismo como uma ação coletiva.

No período observado, de abril de 2014 a abril de 2016, embora tenha sido identificada algumas lideranças de ações nas mãos de técnicos (graduados) e docentes, o que diminui a possibilidade de liderança estudantil, observou-se também seu reverso. Que os trabalhos desenvolvidos pela ITCPUFV se garantem pela ação e participação dos estudantes da graduação, principalmente em tempo de ausência de bolsas, pois, é o interesse deles que garante a existência deste programa de extensão. Além da oportunidade de trabalho, a aspiração por atuar com os grupos populares, e a vontade de fazer a diferença colocam os discentes como protagonistas das ações de extensão, da própria formação e da transformação social. Mesmo os discentes mais tímidos, inseguros ou introspectivos acabam por se transformarem e transformarem as relações a seu redor, a partir do exercício do protagonismo. Neste processo, o papel dos técnicos e dos docentes orientadores seria dar condições para que esta liderança emergisse, e com ela, o aprendizado. Há que se considerar que cada indivíduo tem seu tempo, seu ritmo de aprendizado e desenvolvimento, e o exercício do protagonismo é parte deste processo.

Nós, educadores, precisamos ter clareza do que é aprender, do que é "aprender a aprender", para entendermos melhor o ato de ensinar. Para nós, educadores, não basta saber como se constrói o conhecimento. Nós precisamos dominar outros saberes da nossa difícil tarefa de ensinar. Precisamos saber o que é ensinar, o que é aprender e, sobretudo, como aprender (GADOTTI, 2003, p. 48).

É essa sabedoria que vai nos permitir educar os futuros educadores da Economia Solidária. Outro indicador deste protagonismo foi o que identifiquei na história da incubadora. Do ano de 2012 para 2013 a ITCP esteve em face de encerrar suas ações ou perder sua estrutura por falta de um coordenador que compreendesse e aceitasse trabalhar na dinâmica deste grupo. Em período sem bolsas e sem coordenação, a força política do coletivo discente se constituiu em um ato de resistência que, associado à chegada na UFV de uma docente para ministrar as disciplinas "Desenvolvimento Local e Políticas Públicas" e "Economia Solidária" do DER, possibilitou o resgate de recursos, a consolidação da atual proposta de trabalho e a aprovação de projetos que tornou possível a chegada dos técnicos/as.

\section{6 - Vivência dos valores e princípios da Economia Solidária}

Como característica educativa, a vivência está muito próxima da terceira, o aprendizado pela prática. Preferi separar as duas, pois, entendo a prática como a ação em si, o "pegar e fazer". Já a vivência, requer o acionamento de um leque de competências que envolvem a subjetividade de cada indivíduo, a sua predisposição em fazer parte da ação prática na sua totalidade, o que exige ação técnica e envolvimento emocional. Partindo desta subjetividade produzida por cada indivíduo, vivências e aprendizagens incorporam-se à identidade dos sujeitos em interação, de tal modo que formas de ação pautadas na coletividade possam ter um impacto significativo sobre a identidade dos associados ao processo em questão (VERONESE e ESTEVES, 2019, p. 220). Tiriba e Fischer (2009, p. 293) explica que "a vivência deixa marcas éticas, políticas, culturais e existenciais, além de inúmeros saberes". Coletivamente também se vivenciam modos de ser, produzir e de se reproduzir material, social e culturalmente.

É a partir da vivência das ações que os formadores passam a significar e constituir novas experiências que irão enriquecer o seu currículo. Para Tiriba e Fischer (2009, p. 295), "uma forma de transformação das vivências em experiências acontece através da compreensão do como e do porquê de determinados modos de fazer, pensar ou sentir". Um dos objetivos do trabalho em grupo é a troca de experiência entre os integrantes, o que coloca no processo em execução uma gama de detalhes advinda de vários pontos de vista, permitindo a cada integrante a reafirmar ou reconfigurar seu ponto de vista, de pensar e de agir. Quando realizadas em grupos, essa reorientação cognitiva advinda da vivência compartilhada faria com que "concepção e prática estariam conscientemente articuladas em base sólida para se pensar o passado e o presente e projetar o futuro. Assim, na perspectiva de uma nova cultura do trabalho, os saberes do trabalho associado necessitam ser identificados, reconhecidos e legitimados" (TIRIBA E FISCHER, 2009, p. 293). 
Como processo educativo, é preciso que a vivência esteja alinhada à formação acadêmica, de modo a possibilitar o confronto de conhecimentos, alinhando teórica e prática. Para Freire (1996, p. 92), uma pratica educativa não terá sentido sem um rigor metódico que leve os educandos ao desenvolvimento da disciplina intelectual. Deste modo, a formação acadêmica pela qual os discentes passam, juntamente com a formação teórica/prática que a incubadora propõe, constituem a possibilidade de aplicação destes conhecimentos. Assim, o contato com práticas solidárias faz com que a equipe da ITCP sinta as mesmas emoções que os integrantes dos EES.

\section{7 - Interdisciplinaridade e transdisciplinaridade}

Ao compor sua equipe com indivíduos oriundos dos diversos campos científicos, a incubadora caminha para promoção de ações interdisciplinares. Todavia, esse conceito vai muito além da ação coletiva de várias ciências. Fazenda (1979) evidencia que a interdisciplinaridade é a ação oriunda da integração dos diversos conhecimentos. Ferreira (2001) dispõe que a ação interdisciplinar é marcada por um movimento ininterrupto e pela intencionalidade de pratica-la. Todo indivíduo engajado nesse processo será, não o aprendiz, mas, na medida em que familiarizar-se com as técnicas e quesitos básicos, o criador de novas estruturas, novos conteúdos, novos métodos; será motor de transformação, ou o iniciador dela (FAZENDA, 1979, p. 94). Se a interdisciplinaridade se articula a partir das disciplinas, a extensão universitária dialógica é o caminho para a transdisciplinaridade. Assumpção (1994, p. 24) define a transdisciplinaridade como um movimento para fora do currículo.

Para Fazenda (2001, p. 17) o pensar interdisciplinar parte do princípio de que nenhum conhecimento é em si mesmo racional. Ele depende, pois, do diálogo com outras formas de conhecimento, incluindo aí, o senso comum, onde situa nosso cotidiano. Assim, um trabalho interdisciplinar deve envolver os diversos tipos de conhecimento que parte de cada indivíduo, articulando-o com o coletivo.

No projeto interdisciplinar não se ensina, nem se aprende: vive-se, exerce-se. A responsabilidade individual é marca do projeto interdisciplinar, mas essa responsabilidade está incumbida do envolvimento - envolvimento esse que diz respeito ao projeto em si, às pessoas e às instituições a ele presente (FAZENDA, 2001, p. 17).

O que se pretende na interdisciplinaridade não é anular a contribuição de cada ciência em particular, mas apenas uma atitude que venha a impedir que se estabeleça a supremacia de determinada ciência, em detrimento de outros aportes igualmente importantes (FAZENDA, 1979, p. 59). Para Thiesen (2008, p. 550) ainda é incipiente, o desenvolvimento de experiências verdadeiramente interdisciplinares, embora haja um esforço institucional nessa direção. O autor explicita que, um dos motivos está na forma fragmentada como o currículo está organizado nas universidades. Fazenda $(1979$, p. 78$)$ coloca que a interdisciplinaridade é fator de transformação, de mudança social. Menezes (2001) coloca a transdisciplinaridade como princípio considera que embora cada um dos campos guarde suas especificidades, há entre eles um intercâmbio permanente, formando novos campos. Neste sentido, mesmo diante das dificuldades em articular os trabalhos com os currículos, a incubadora consegue articular os dois conceitos em suas ações.

\section{Conclusão}

As características do processo educativo realizado pela Incubadora Tecnológica de Cooperativas populares da UFV, apesar de apresentadas de forma fragmentada, devem ser olhadas de forma integrada, incluindo-se aí outros elementos, como a estrutura e a rede de apoiadores. Nessa perspectiva, a ITCP-UFV apresenta uma prática educativa bem organizada e estruturada de forma a permitir a seu coletivo a vivência de uma pedagogia da autogestão, algo a ser construído com os membros de empreendimentos solidários.

Talvez fosse interessante a incubadora construir um projeto político pedagógico que deixasse evidente os propósitos da ação educativa. Este deveria responder à pergunta "qual a mulher ou o homem a incubadora deseja que seus formadores sejam na sociedade?". A resposta a tal questão ajudaria a colocar no papel o que já ocorre em suas práticas educativas, e por consequência, nortearia a formação coletiva.

Quanto às características educativas da incubadora, se o foco aqui foi a compreensão de seu processo formativo, para além do que foi mostrado, o próximo passo seria descobrir os resultados deste processo. Com esse intuito, pode-se identificar a trajetória profissional daqueles/as ex-formadores/ as da incubadora. Onde estão? Em que trabalham? Qual a contribuição da vivência na ITCP para sua 
vida profissional? Acredito que a junção dos resultados aqui obtidos com esta análise permitirá avaliar com mais densidade as reais contribuições da extensão universitária para a formação destes profissionais. Além disso, parece-me necessário que outros programas e projetos de extensão olhem para as próprias práticas formativas, tendo em vista que é a partir da atuação discente que a extensão ocorre.

Por fim, a proposta de pesquisa etnográfica é um caminho para que o próprio pesquisador avalie suas práticas. Se ingressei na incubadora graduado em cooperativismo, diante dos desafios enfrentados na busca da compreensão deste processo formativo, percebi que carecia de uma compreensão maior sobre o que é a educação. Assim, hoje sou graduando em pedagogia, e com ela, busco uma prática educacional que realmente leve os educandos à construção da própria autonomia.

\section{Fontes de financiamentos}

Fundação de Amparo à Pesquisa do Estado de Minas Gerais (FAPEMIG), pelo financiamento dos projetos de pesquisa com interface em extensão que subsidiaram este estudo: Processo: APQ-03349-14 - O Papel do Movimento Social na Construção de Políticas Públicas Locais: A Experiência do Fórum Regional de Economia Solidária da Zona da Mata Mineira; e Processo APQ-02519-16 - Economia Solidária, Políticas Públicas e o Setor da Reciclagem: análise da coleta seletiva e geração de trabalho e renda para os catadores de materiais recicláveis do município de Viçosa - MG.

Conselho Nacional de Pesquisa e Desenvolvimento (CNPQ): Projeto Ressoa na Mata: Redes de Economia Solidária e Agroecologia na Zona da Mata de Minas gerais - processo 441897/2017-7

\section{Agradecimentos}

Agradeço a todo o coletivo da ITCP-UFV pela experiência de educação e trabalho na Economia Solidária, e em especial, à professora Bianca A. Lima Costa e ao professor Marcio Gomes da Silva, pelos 4 anos, 2 meses e 8 dias em que me senti parte deste coletivo. Ao Programa de Educação Tutorial - PET Educação - Conexões de Saberes, do curso de Pedagogia, Departamento de Educação.

\section{Referências bibliográficas:}

ANDRÉ, M. E. D. A. Etnografia da prática escolar. Campinas, SP: Papirus, 1995.

ARELARO, L. R. G. A pedagogia da terra: novos ventos na universidade. In: KRUPPA, S. M. P. Economia Solidária e Educação de Jovens e adultos. Brasília: Editorial Inep/MEC - Instituto Nacional de Estudos e Pesquisas Educacionais Anísio Teixeira, 2005.

ASSUMPÇÃO, I. Interdisciplinaridade: uma tentativa de compreensão do fenômeno. In BOGDAN, R.; BIKLEN, S. Investigação qualitativa em educação: uma introdução a teoria e aos métodos. Porto: Editora Porto, 1994.

BERTH, J. O que é empoderamento. Belo Horizonte: Editora Letramento, 2008.

BOGDAN, R.; BIKLEN, S. Investigação qualitativa em educação: uma introdução a teoria e aos métodos. Porto: Editora Porto, 1994.

BORGES, T. P. Os atores da economia solidária: um estudo sobre personalidade ética. São Paulo: Universidade de São Paulo, 2014.

BOTELHO, L. L. R et al. As. Incubadoras Tecnológicas de Cooperativas Populares: Atuando a partir da extensão universitária. In: XV Colóquio Internacional de Gestão Universitária - CIGU - 2015, Florianópolis.

BRASIL. Ministério do Trabalho e Previdência Social. Sistema Nacional do Comércio Justo e Solidário - SCJS, Secretaria Nacional de Economia Solidária. 2010a. Disponível em: <http:// www.planalto.gov.br/ccivil_03/_ato2007-2010/2010/decreto/d7358.htm>. Acesso em 12 set. 2018.

BRASIL. Economia solidária: caderno pedagógico educandas e educandos. Brasília: Ministério da Educação, Secretaria de Educação Continuada, Alfabetização e Diversidade, 2010b.

BRASIL. $1^{0}$ Plano Nacional de Economia Solidária. Conselho Nacional de Economia Solidária, 2015. 
CARDOZO, M. C. O trabalho em equipe e seus motivadores. 2003. Dissertação (Mestrado em Administração) Escola de Administração de Empresas. Fundação Getúlio Vargas. São Paulo: 63p.

COSTA, B. A. L. Política Pública de Economia Solidária no Estado de Minas Gerais: Conflitos e convergências na construção de novas ações de geração de trabalho e renda. In: Congresso LusoAfro-Brasileiro de Ciências Sociais, 2011, Salvador. Disponível em: < https:// bit.ly/2xCyO1W >. Acesso em 4 out 2015.

COSTA, B. A. L. Economia solidária e o papel das incubadoras tecnológicas de cooperativas populares no Brasil: a experiência de extensão universitária da ITCP-UFV. Revista ELO - Diálogos em Extensão, v. 02, n. 02, p. 17 - 34. dezembro de 2013.

COSTA, B. A. L.; SILVA, M. G. DOURADO, G. F. (Org.). Saberes construídos na economia solidária: experiências e vivências da Incubadora Tecnológica de Cooperativas Populares da UFV. $1^{\circ}$ ed. Viçosa: Organização Cooperativa de Agroecologia, 2017.

CUNHA, J. A. C.; RIBEIRO, E. M. S. A Etnografia como Estratégia de Pesquisa Interdisciplinar para os Estudos.Qualit@s Revista Eletrônica, v.9, n. 2, p. 1 - 17. 2010.

FAZENDA, I. C. A. Integração e Interdisciplinaridade no Ensino Brasileiro. São Paulo: Edições Loyola, 1979.

FAZENDA, I. C. A. Práticas interdisciplinares na escola. 8. ed. São Paulo: Cortez, 2001.

FERREIRA, S. L. Introdução à noção de interdisciplinaridade. In: FAZENDA, I. C. A. Práticas interdisciplinares na escola. 8. ed. São Paulo: Cortez, 2001.

FERREIRA, R. A. O desgaste de termos como "empoderamento" e "protagonismo". Jornal da USP Artigos - 2017, On-line.

FÓRUM DE PRÓ-REITORES DE EXTENSÃO DAS INSTITUIÇÕES PÚBLICAS DE EDUCAÇÃO SUPERIOR BRASILEIRAS [FORPROEXT]. Política Nacional de Extensão Universitária. 2012: Rio de Janeiro, RJ.

FRANÇA FILHO, G. C. (Orgs.). Ação Pública e economia solidária: uma perspectiva internacional. Porto Alegre: Editora da UFRGS, 2006, p. 201 - 206.

FREIRE, P. Extensão ou Comunicação? 10 Ed. São paulo: Editora Paz e Terra. 1977.

FREIRE, P. Pedagogia do oprimido. 5 ed. rev. e atual. Rio de Janeiro: Paz e Terra, 1991.

FREIRE, P. Pedagogia da autonomia: saberes necessários à prática educativa. São Paulo: Paz e Terra, 1997.

FREIRE, P. Educação como prática de liberdade: a sociedade brasileira em transição. Rio de Janeiro, Paz e Terra, 2000.

GADOTTI, M. Boniteza de um sonho: ensinar-e-aprender com sentido. Novo Hamburgo: Feevale, 2003.

GADOTTI, M. Economia solidária como práxis pedagógica. São Paulo: Editora e Livraria Instituto Paulo Freire, 2009.

GAIGER, J. L.; LAVILLE, L. I. Economia Solidária. In: CATTANI, A. D; LAVILLE, J. J; GAIGER, L. I; HESPANHA, P. Dicionário internacional da outra economia. Coimbra: Editora Almedina, 2009, p. $162-168$.

KRUPPA, S. M. P. Economia solidária e Educação de Jovens e Adultos. Brasília: INEP; Campinas SP: Papirus Editora, - 2005 (Coleção Magistério: Formação e Trabalho Pedagógico).

LOVATO, A.; YIRULA, C. P.; FRANZIM, R. Protagonismo: a potência da ação da comunidade escolar. São Paulo: Ashoka/Alana, 2017.

MATHEUS, M. C. C. O trabalho em equipe: um instrumento básico e um desafio para a enfermagem. Rev. Esc. Enf. USP, v.29, n.1, p. 13-25, abr. 1995.

MATTOS, C. L. G. Etnografia e educação: conceitos e usos. Campina Grande: EDUEPB, 2011.

Disponível em: <http://books.scielo.org>. Acesso em: 10 set. 2018. 
MENEZES, E. T.; SANTOS, T. H. Transdisciplinaridade. In: Dicionário Interativo da Educação

Brasileira - Educabrasil. São Paulo: Midiamix, 2001. Disponível em: $<$ https://bit.ly/2zy3qmN>. Acesso em: 20 de set. 2018.

MORAES, R. Análise de conteúdo. Revista Educação, Porto Alegre, v. 22, n. 37, p. 7-32, 1999.

PRÓ-REITORIA DE EXTENSÃO E CULTURA [PEC UFFS]. Programa de ações interdisciplinares em pesquisa, ensino e extensão: alteridade, processos identitários e educação. Disponível em: < https:// bit.ly/2O8R8JJ >. Acesso em 16 de set. 2018.

RODRIGUES, D. C. M. Educação e trabalho na perspectiva da economia solidária: Experiências na comunidade Sol Nascente. Brasília: Universidade Federal de Brasília - UNB, Faculdade de Educação, 2014. Disponível em: <https://goo.gl/YAYiYQ>. Acesso em 29 de ago. de 2018.

RUFINO, S.; BARBIERI, L. A gestão da autogestão nas cooperativas. In: Incubadora Tecnológica de Cooperativas Populares. In: ____. (Org.). A gestão da autogestão na Economia Solidária: contribuições iniciais. São Paulo: ITCP-USP, 2008.

SANDÍN ESTEBAN, M. P. Pesquisa qualitativa em educação: fundamentos e tradições. Porto Alegre: AMGH, 2010.

SANTOS, A. M.; CARNEIRO, V. O movimento da economia solidária no Brasil: uma discussão sobre a possibilidade de unidade através da diversidade. E-cadernos CES (Online), v. 1, 2008.

SANTOS, A. M; CRUZ, A.C.M. Incubadoras Tecnológicas de Cooperativas Populares: interdisciplinaridade articulando ensino, pesquisa e extensão universitária. E-cadernos CES (Online), 2008.

SCHIOCHET, V. Institucionalização das Políticas Públicas de Economia Solidária: Breve trajetória e desafios. Brasília: IPEA/Ministério do Trabalho e Emprego, 2009.

SILVA, S. L. P. Histórico da Economia Solidária no Brasil. Congresso Brasileiro de Pesquisadores em Economia Solidária, UFSCAR, 2015.

SILVA, T. T. O Discurso Pedagógico da Sociologia da Educação: Crítica da Crítica? In: MOREIRA, A. F. (Org.) Conhecimento educacional e formação de professor. 2 ed. Campinas: Editora Papirus, 1995.

SINGER, P. Uma utopia militante: repensando o socialismo. 2 ed. Petrópolis: Vozes, 1999.

SINGER, P. Introdução à Economia Solidária. São Paulo: Fundação Perseu Abramo, 2002.

SINGER, P. Introdução. In: MELLO, S. L. (org.). Economia solidária e autogestão: encontros internacionais. São Paulo: Nesol/USP, 2005a.

SINGER, P. A Economia Solidária como ato pedagógico. In: KRUPPA, S. M. P. Economia solidária e Educação de Jovens e Adultos. Brasília: INEP; Campinas SP: Papirus Editora, 2005b (Coleção Magistério: Formação e Trabalho Pedagógico).

THIESEN, J. S. A interdisciplinaridade como um movimento articulador no processo ensinoaprendizagem. Revista Brasileira de Educação, v. 13, n. 39, 545 - 598, set./dez. 2008.

TIRIBA, L.; FISCHER, M. C. B. Saberes do trabalho associado. In: CATTANI, A. D; LAVILLE, J. J; GAIGER, L. I; HESPANHA, P. Dicionário internacional da outra economia. Coimbra: Editora Almedina, 2009, p. 293 - 298.

UNIVERSIDADE DE SÃO PAULO [USP]. Guia de Apresentação de Teses. Biblioteca Digital São Paulo. 2 ed., 2017. Disponível em:<http://www.biblioteca.fsp.usp.br/ biblioteca/guia/ i_cap_04.htm>. Acesso em 23 de abril de 2019

VERONESE, M. V.; ESTEVES, E. G. Identidade. In: CATTANI, A. D; LAVILLE, J. J; GAIGER, L. I; HESPANHA, P. Dicionário internacional da outra economia. Coimbra: Editora Almedina, 2009, p. 219 - 223.

Data de submissão: 30/10/2018. Data de aceite: 22/4/2019. 